\title{
Proposed Conceptual Iot-Based Patient Monitoring Sensor for Predicting and Controlling Dengue
}

\author{
Noor Hafizah Hassan ${ }^{1}$, Ely Salwana ${ }^{2}$, Sulfeeza Md. Drus ${ }^{3}$, Nurazean Maarop ${ }^{4}$, \\ Ganthan Narayana Samy ${ }^{5}$ and Noor Azurati Ahmad ${ }^{6}$ \\ ${ }^{1}$ Advanced Informatics School, Universiti Teknologi Malaysia, Kuala Lumpur \\ ${ }^{2}$ Institute of Visual Informatics, Universiti Kebangsaan Malaysia, Selangor \\ ${ }^{3}$ CSIT, Universiti Tenaga Nasional, Selangor \\ ${ }^{4,5,6}$ Advanced Informatics School, Universiti Teknologi Malaysia, Kuala Lumpur \\ ${ }^{1}$ noorhafizah.kl@utm.my, ${ }^{2}$ elysalwana@ukm.edu.my, ${ }^{3}$ sulfeeza@uniten.edu.my \\ 4nurazean.kl@utm.my, ${ }^{5}$ ganthan.kl@utm.my, ${ }^{6}$ azurati@utm.my
}

\begin{abstract}
Dengue is an epidemic-disease by mosquito-borne virus that spreads easily in geographically affected areas. Dengue outbreak management system has increasingly being developed in identifying and controlling the spread of dengue but with some limitation. The growing development of wearable Internet of Things (IoT), cloud computing, analytical approaches provide better alternative for dengue prediction and control. Previous literature collecting various parameters for analyzing dengue pattern. However, with the increasing number of analytical solution there is a need to investigate the high related parameters that should be use in analyzing and monitoring dengue outbreak before designing an IoT devices. Besides, there is a need for an alternative to ensure that early warning can be detected by monitoring the patient infected by the dengue, this paper aims to propose a conceptual IoT-based patient monitoring sensor for predicting and controlling dengue outbreak. Therefore, this paper provides a recent review of the latest methods and algorithms used to design wearable sensor for patient monitoring in dengue outbreak. Based on the review, this paper outlines the parameters that will be used in dengue for analyzing purposes. Finally, a conceptual IoT-based patient monitoring sensor were proposed comprising three different sensors to further work with analytical tools for dengue prediction pattern. The proposed conceptual design may help researcher to use the parameter identified for development of IoT sensor for dengue outbreak.
\end{abstract}

Keywords: Dengue Prediction, Internet of things, Patient Monitoring Sensor, medical informatics

\section{Introduction}

Dengue outbreak is increasingly high and has been grown rapidly and its outbreak results in acute illness that may lead to chronic phase. The rise of dengue incident reported has grown dramatically around the world for the last decades. In Malaysia, it has been reported from iDengue portal; a portal developed to show the outbreak of dengue that shows a total of 56,496 dengue cases was reported from 1st Jan to 25th July 2017. The actual spatial scale used in the models varied from community level to multi-country [1]. In Thailand, socio-environmental changes have been identified as important determinants in the transmission of dengue. Spatial and temporal aspects of these changes have been increasingly incorporated into studies [2].

Received (August 28, 2017), Review Result (November 18, 2017), Accepted (November 26, 2017) 
Possibly infected users should be examined at an early stage of dengue so that they will not contributing in spreading the dengue infection. Though a number of on-going research efforts are focusing on various technical, economic, and social issues, many technical hurdles still need to be resolved in order to have flexible, reliable, secure, and powerefficient solution that is suitable for medical application. The evolution of IoT in healthcare application may enhance life quality specifically for dengue patient that need to be monitored Currently, in another diseases the evolution of analytics in healthcare may help to predict heart disease risk and medications with the support of (Internet of Things) IoT based monitoring system [3]. This concept can also be apply to predict and control dengue infections that adopt cloud computing and big data concept that capture daily healthcare related information using health data mining algorithm[4]. The system can be used to find out the correlation between a health condition and lifestyle to provide early warning of dengue infections. Based on the environment of dengue epidemic discussed, this paper sought to identify climate or meteorological data and related clinical data influence on dengue outbreak in Malaysia. Therefore, a review of related literature on dengue and patient monitoring sensor were conducted. Then, a conceptual IoT-Based Patient Monitoring Sensor for Predicting and Controlling Dengue is proposed with identified parameters is presented.

\section{Patient Monitoring Sensor}

In a hospital or clinic, outfitting every patient with tiny, wearable wireless vital sign sensors would allow doctors, nurses and other caregivers to continuously monitor the status of their patients. In an emergency or disaster scenario, the same technology would enable medics to more effectively care for large numbers of casualties. First, responders could receive immediate notifications on any changes in patient status, such as respiratory failure or cardiac arrest. Technology assisted-growth shows that there is great variety running sensor reading vital signs such as blood pressure cuff, glucometer, heart rate monitor, including electrocardiograms, which allow patients to take their vital signs daily [7]. The concept of IoT defined as the integration of all devices that connect to the network, which can be managed from the web and in turn provide information in real time, in order to allow interaction with people for the purpose of patient monitoring [8].

The advancement of technology for improving quality of health care delivery have led towards the implementation of IoT in patient monitoring. Researchers across the world have started to explore various technological solutions to enhance healthcare provision in a manner that complements existing services by mobilizing the potential of the IoT. .A number of work on IoT related for chronic disease monitoring system captured vital signs data via medical sensors, data mining algorithms to analyze the data and accessible by medical practitioner [7], [9]. However, this work only captures vital sign regardless of environmental factors. The medical data transferred later can be adapt with big data analysis technologies to be used as guide in lifestyle, as a tool to support in the decisionmaking, and as a source of innovation in the evolving healthcare ecosystem [10].

\section{Related Works on Dengue}

The infected cases dengue in Malaysia are reported on daily basis by the Ministry of Health (MOH), Malaysia and published online as in http://idengue.remotesensing.gov.my/. The web shows that increasing rate of dengue fever in Malaysia as of today's date. Recently, [11] have reported the current status of dengue in Malaysia and proposed future development of vaccination and specifically stressed on the important of having a proper dengue control management to ensure that society understand the risk of this potentially global threat. In Malaysia, a study shows that the importance of detailed geographical analysis of dengue cases in heterogeneous environments with a focus on clustered populations at different 
spatial and temporal scales as an important step towards the development of an effective risk management strategy [12]. Majority of the studies in Malaysia indicated an association between dengue, rainfall, and temperature [13].

In Delhi, predictive analysis from [14] shows that number of dengue cases are decreased during the period of maximum rainfall and cold temperature. These findings supported by [15] in Indonesia, Malaysia [16], and Vietnam [17] that shows high temperature have a strong impact on dengue outbreak. In Pakistan, it also indicate that warming temperatures might extend the period of mosquito activity and the duration of disease transmission [18]. Therefore, it can be concluded that climate are the important variables for the prediction of dengue cases. Besides the climate/environmental parameters, clinical record parameters are also important variable that influence dengue infection. A predictive model using decision trees classifications to detect dengue fever based on clinical history records of particular patient such as fever, fever duration, headache and related laboratory result has been proposed [19] and improved the accuracies of prediction in dengue fever. Another work from [20] use another two variables which are vital sign and blood profile of the dengue patients in dengue management practices for predicting and classify dengue patients. Clinical laboratory variables and patient characteristic can be used to distinguish patients with severe illness from those with mold dengue illness [21]. The next sections describe body and environmental parameters that have been used in previous research for designing IoT wearable sensor. Environmental factor known as a risk factor such as humidity, sea surface temperature, geographical settings, temperature, precipitation, wind velocity, geographical settings, hygienic parameters, and socio environmental factors (population) were some of the factors related to dengue fever. Despite of predictive modeling on early detection of dengue fever, early work on developing a sensor to differentiate female Aedes mosquito through frequency differences [22] has been proposed.

\subsection{Body Parameters}

The condition for dengue patients' body parameters need to be continuously monitored in any critical condition of plasma leakage in order to minimize the case fatality rate of dengue [23]. A wireless continuous patient monitoring system for dengue may assist the monitoring process [24]. Table 1 shows the related work on patient monitoring sensor.

Table 1. Related Work on Patient Monitoring Sensor

\begin{tabular}{|l|l|l|l|}
\hline Author & Wireless Technology & \multicolumn{1}{|c|}{ Sickness } & \multicolumn{1}{c|}{ Parameters } \\
\hline$[25]$ & WSN & $\begin{array}{l}\text { General } \\
\text { Sickness }\end{array}$ & $\begin{array}{l}\text { Movement characteristics, heartbeat, } \\
\text { breath, proximity to other patients }\end{array}$ \\
\hline$[26]$ & WSN and AUR & $\begin{array}{l}\text { General } \\
\text { Sickness }\end{array}$ & Heart Rate, Temperature \\
\hline$[27]$ & $\begin{array}{l}\text { Fog Computing, } \\
\text { RFID, GPS }\end{array}$ & Chikungunya & Health related parameters \\
\hline$[28]$ & $\begin{array}{l}\text { Bluetooth } \\
\text { Technology }\end{array}$ & $\begin{array}{l}\text { General } \\
\text { Sickness }\end{array}$ & $\begin{array}{l}\text { Patient Position, Glucometer, } \\
\text { Temperature, Blood Pressure, Pulse- } \\
\text { oximeter, Respiration, Galvanic Skin } \\
\text { Response, ECG }\end{array}$ \\
\hline$[29]$ & Bluetooth, WI-If & Patient in ICU & $\begin{array}{l}\text { blood pressure, heart beat rate, body } \\
\text { temperature, body position }\end{array}$ \\
\hline$[30]$ & RFID & Chronic disease & $\begin{array}{l}\text { Electrocardiogram (ECG) Glucose } \\
\text { Sensor }\end{array}$ \\
\hline$[24]$ & $\begin{array}{l}\text { Wireless Body Area } \\
\text { Network }\end{array}$ & Dengue & $\begin{array}{l}\text { Blood Pressure, Heart Rate, } \\
\text { Temperature, Oxygen level }\end{array}$ \\
\hline
\end{tabular}




\subsection{Environmental Parameters}

Related literatures from 2012 to 2017 have been reviewed for identifying the parameters that are related on dengue outbreak as shown in Table 2. The table shows the earlier work on predicting dengue outbreak based on environmental or meteorological data.

Table 2. Related Work on Environmental Parameters for Dengue

\begin{tabular}{|c|c|c|c|}
\hline Authors & Methodology & Country & Parameters \\
\hline [31] & Social Network Analytics & Worldwide & $\begin{array}{l}\text { Dengue cases, Tweets on "Dengue", } \\
\text { "aedes" and "aegypti", }\end{array}$ \\
\hline [32] & $\begin{array}{l}\text { Regression and Binning } \\
\text { Classification }\end{array}$ & Thailand & $\begin{array}{l}\text { rainfall, dengue cases, vegetation index } \& \\
\text { temperature, brightness temperature }\end{array}$ \\
\hline [33] & K- Means Clustering & Selangor & temperature, rainfall and humidity \\
\hline [34] & Permutation & Hong Kong & $\begin{array}{l}\text { Dengue Cases, Temperature, Rainfall, } \\
\text { Sunshine, Wind Speed }\end{array}$ \\
\hline [35] & $\begin{array}{l}\text { ARIMA and ARIMAX } \\
\text { model }\end{array}$ & $\begin{array}{l}\text { Surabaya, } \\
\text { Indonesia }\end{array}$ & $\begin{array}{l}\text { Total dengue cases, dengue, demam } \\
\text { berdarah, demam, dbd }\end{array}$ \\
\hline [36] & $\begin{array}{lr}\text { Moderate resolution } \\
\text { imaging spectroradiometer }\end{array}$ & Argentina & $\begin{array}{l}\text { normalized difference vegetation index, } \\
\text { land surface temperature, sum egg catches }\end{array}$ \\
\hline [37] & Mathematical Model & Singapore & $\begin{array}{l}\text { dengue cases, incubation period for } \\
\text { human and mosquito }\end{array}$ \\
\hline [38] & Gaussian Process & Brazil & Dengue cases, temperature, humidity \\
\hline [39] & Statistical Analysis & Selangor & Dengue cases, land temperature, elevation \\
\hline [14] & Linear Regression (R-tool) & India & Dengue cases \\
\hline [15] & Granger casuality & Vietnam & $\begin{array}{l}\text { Dengue cases, temperatures, humidities, } \\
\text { rainfall, hours of sunshine }\end{array}$ \\
\hline [40] & Artificial Neural Network & Philippine & $\begin{array}{l}\text { Dengue cases, temperature, rainfall, } \\
\text { humidity }\end{array}$ \\
\hline [41] & $\begin{array}{l}\text { C-Support Vector } \\
\text { Classification }\end{array}$ & Taiwan & $\begin{array}{l}\text { Year, Number of Week, Longitude, } \\
\text { Latitude, Temperature, Precipitation }\end{array}$ \\
\hline [16] & K-means clustering & $\begin{array}{l}\text { Selangor, } \\
\text { Malaysia }\end{array}$ & $\begin{array}{l}\text { Dengue cases, notification id, year, } \\
\text { coordinates, area, diagnosis, sub diagnosis }\end{array}$ \\
\hline [42] & $\begin{array}{l}\text { Moran's I, Average } \\
\text { Nearest Neighbor, Kernel } \\
\text { Density Estimation }\end{array}$ & $\begin{array}{l}\text { Selangor, } \\
\text { Malaysia }\end{array}$ & $\begin{array}{l}\text { Location, dengue cases, date start and last } \\
\text { case, period outbreak occurs, outbreak } \\
\text { expected. }\end{array}$ \\
\hline [17] & Regression model & $\begin{array}{l}\text { Mekong Delta, } \\
\text { Vietnam }\end{array}$ & $\begin{array}{l}\text { Dengue cases, temperature, rainfall, } \\
\text { humidity }\end{array}$ \\
\hline [18] & Time-series models & $\begin{array}{l}\text { Lahore, } \\
\text { Pakistan }\end{array}$ & $\begin{array}{l}\text { temperature, precipitation, humidity, } \\
\text { dengue cases }\end{array}$ \\
\hline [43] & $\begin{array}{l}\text { Distributed lag non-linear } \\
\text { models, Generalised } \\
\text { estimating equation }\end{array}$ & $\begin{array}{l}\text { Guangzhou } \\
\text { china }\end{array}$ & $\begin{array}{l}\text { temperatures, rainfall, average relative } \\
\text { humidity, sunshine duration, and } \\
\text { maximum wind velocity }\end{array}$ \\
\hline [44] & Linear Regression & $\begin{array}{l}\text { Yucatan, } \\
\text { Mexico }\end{array}$ & $\begin{array}{l}\text { Dengue cases, precipitation, maximum, } \\
\text { temperature }\end{array}$ \\
\hline [45] & Linear Regression & $\begin{array}{l}\text { Dhaka city, } \\
\text { Bangladesh }\end{array}$ & $\begin{array}{l}\text { Dengue cases, temperature, rainfall, } \\
\text { humidity }\end{array}$ \\
\hline [46] & $\begin{array}{l}\text { Fuzzy Association Rule } \\
\text { Mining }\end{array}$ & Peru & $\begin{array}{l}\text { Dengue cases, rainfall, temperature, and } \\
\text { socio-economic data }\end{array}$ \\
\hline
\end{tabular}




\section{Proposed Conceptual Design}

Based on the review conducted, a proposed conceptual design comprises the sensors and parameters is presented in Figure 1. The sensor developed using WSN technology to sense and record vital signs and environmental parameters into cloud environment for analysis purposes. There are three type of sensor:

a. Wearable Sensor-Body temperature, heart-beat, blood pressure,

b. Outdoor and Indoor Environment Sensor- Temperature, rainfall, humidity, air quality

Additionally, secure data storage in the cloud will be designed. When the medical records are outsourced to the cloud for storage, appropriate privacy preserving measures need to be taken to prevent unauthorized parties from accessing the information. Cloud computing will be incorporated in this monitoring system. Security concept such as public and private key encryption will be applied while developing the sensor. In the data collection layer, various healthcare data are collected by the data nodes and are transmitted to the cloud through the configurable adapters that provide the functionality to preprocess and encrypt the data. The data received from the sensor will be analyzed using data analytics tool for better understanding and efficient decision making in the descriptive and predictive context in monitoring dengue patients for healthcare management.

Figure 1 shows the proposed conceptual design for IoT-based Patient Monitoring Sensor for Dengue patients. It shows that three devices or sensors need to be installed in the patients house if any patients has been diagnosed with dengue. It has been proposed that the design comprises of three layers which are sensor layer, network layer and interface layer. Table 3 shows the summary of the possible criteria that can be choose to propose in achieving the design goals of the proposed IoT conceptual design. However, there are few challenges that need to be addressed in details in ensuring the success implementation of IoT in monitoring dengue outbreak.

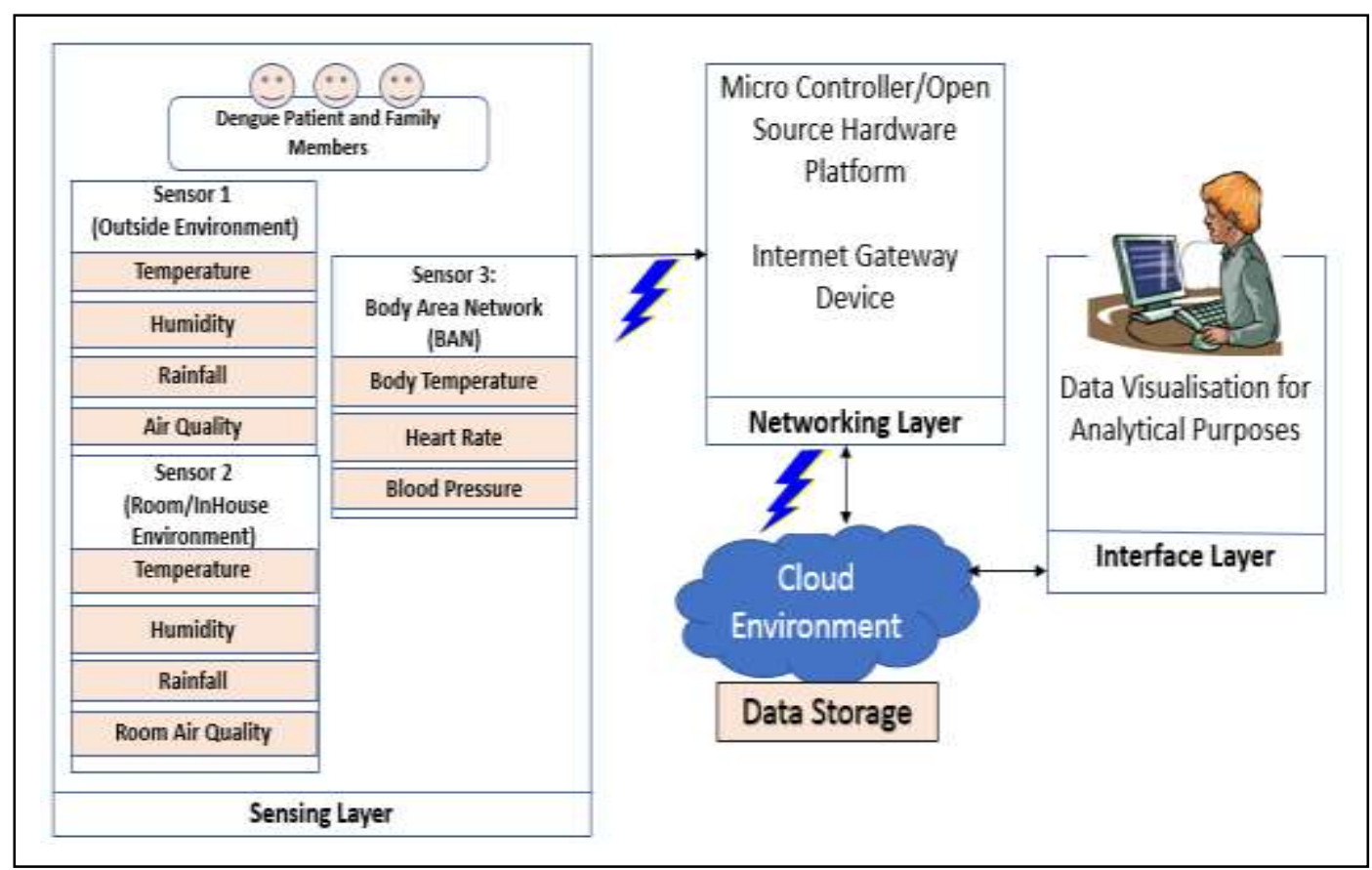

Figure 1. Proposed Conceptual Design of IoT-based Patient Monitoring Sensor for Dengue 
Table 3. Design Consideration for IoT Devices

\begin{tabular}{|l|l|l|}
\hline Design Goals & Criteria & Challenges \\
\hline $\begin{array}{l}\text { Communication Protocols } \\
\text { Sensing Layer to Network } \\
\text { Layer) }\end{array}$ & ZigBee,Wi-Fi and Bluetooth & \\
\cline { 1 - 2 } $\begin{array}{l}\text { Communication Protocols } \\
\text { (Network Layer to Cloud } \\
\text { Storage) }\end{array}$ & MQTT/CoAP/HTTP & $\begin{array}{l}\text { Acceptance, } \\
\text { complexity, cost, data } \\
\text { transmission security, } \\
\text { privacy issues, data } \\
\text { integrity and policy }\end{array}$ \\
\cline { 1 - 2 } Microcontroller & Arduino/ Raspberry-Pi & \\
\hline Energy Source & Main and Energy-Powered & \\
\hline Latency & 5minutes for data & \\
\hline Storage & Cloud Storage & \\
\hline
\end{tabular}

\section{Discussion and Conclusion}

IoT in healthcare can decrease barriers for monitoring related health parameters, as well as avoiding unnecessary healthcare costs and efforts. Further, it also can provide right medical support for predicting and controlling dengue. Therefore, a proposed conceptual design called as an IoT-based patient monitoring sensor for predicting and controlling dengue has been presented with related parameters identified. Three sensors are proposed which are i) wearable sensor, ii) indoor sensor, iii) outdoor sensor. The identified parameters were chosen based on the reviews conducted on several previous related studies. The sensor will be able to collect physiological information and environmental data that uses gateway and cloud to analyze and store all the information that need to be sent to the medical officer. The analyzed data will be used by the medical officer in healthcare organization for decision making purposes that can be further be visualized in dashboard to update the predictive factors and controlling the dengue outbreak. The limitation of this paper that it is not cover in depth the architectural elements of the IoT design that will be further investigated together with the challenges of implementing IoT in healthcare industry. Challenges such as acceptance, complexity, data transmission security and privacy issues needs to be highlighted further.

\section{References}

[1] V. Racloz, R. Ramsey, S. Tong and W. Hu, "Surveillance of dengue fever virus A review of epidemiological models early warning systems", PLoS Neglected Tropical Diseases, vol. 6, no. 5, (2012).

[2] T. J. Sheehan and L. M. DeChello, "A space-time analysis of the proportion of late stage breast cancer in Massachusetts", 1988 to 1997., International Journal of Health Geographics, vol. 4, no. 15, (2005).

[3] A. B. Chavanpatil and P. S. S. Sonawane, "To Predict Heart Disease Risk and Medications Using Data Mining Techniques With an IoT Based Monitoring System For Post Operative Heart Disease Patients", Proc J on Emerging Trends in Technology (IJETT), vol. 4, (2017), pp. 8274-8281.

[4] M. Bhavani and S. V. Kumar, "A Data Mining Approach for Precise Diagnosis of Dengue Fever", Internal J.l of Latest Trends in Engineering and Today, vol. 7, no. 4, (2016), pp. 352-359.

[5] D. W. Bates, S. Saria, L. Ohno-Machado, A. Shah and G. Escobar, "Big data in health care: Using analytics to identify and manage high-risk and high-cost patients", Health Affairs, vol. 33, no. 7, (2014).

[6] M. Palaniyandi, "The environmental aspects of dengue and chikungunya outbreaks in India: GIS for epidemic control”, Int. J. of Mosquito Research IJMR, vol. 35, no. 12, (2014), pp. 35-40.

[7] A. Raji, P. Golda Jeyasheeli and T. Jenitha, "IoT based classification of vital signs data for chronic disease monitoring", Proceedings of the 10th International Conference on Intelligent Systems and Control, (2016).

[8] R. Kumar and M. P. Rajasekaran, “An IoT based patient monitoring system using raspberry Pi”, in 2016 International Conference on Computing Technologies and Intelligent Data Engineering (ICCTIDE'16), (2016), pp. 1-4.

[9] V. Shnayder, B. Chen, K. Lorincz, T. R. F. Fulford-Jones and M. Welsh, "Sensor Networks for Medical Care", (2005).

[10] Y. Zhang, M. Qiu, C. W. Tsai, M. M. Hassan and A. Alamri, "Health-CPS: Healthcare cyber-physical system assisted by cloud and big data", IEEE Systems Journal, vol. 99, (2015). 
[11] E. L. Pang and H. S. Loh, "Current perspectives on dengue episode in Malaysia", Asian Pacific J. of Tropical Medicine, vol. 9, no. 4, (2016), pp. 395-401.

[12] C. Y. Ling, O. Gruebner, A. Krämer and T. Lakes, "Spatio-temporal patterns of dengue in Malaysia: Combining address and sub-district level", Geospatial Health, vol. 9, no. 1, (2014), pp. 131-140.

[13] Y. L. Hii, R. A. Zaki, N. Aghamohammadi and J. Rocklöv, "Research on Climate and Dengue in Malaysia: A Systematic Review", Current environmental health reports, vol. 3, no. 1, (2016), pp. 81-90.

[14] S. Das and A. Thakral, "Predictive Analysis of Dengue and Malaria", Proceedings of International Conference on Computing, Communication and Automation (ICCCA2016), (2016), pp. 172-176.

[15] P. N. Hoang, J. Daniel Zucker, M. Choisy and H. T. Vinh, "Causality analysis between climatic factors and dengue fever using the Granger causality", Proceeding of IEEE RIVF International Conference on Computing and Communication Technologies, (2016), pp. 49-54.

[16] N. Mathur, V. S. Asirvadam, S. C. Dass and B. S. Gill, "Generating vulnerability maps of dengue incidences for Petaling district in Malaysia", Proceeding of IEEE 12th Int. Colloquium on Signal Processing and its Applications, (2016) March, pp. 227-232.

[17] D. Phung, C. Huang, S. Rutherford, C. Chu, X. Wang, M. Nguyen, N. H. Nguyen, and C. Do Manh, "Identification of the prediction model for dengue incidence in Can Tho city, a Mekong Delta area in Vietnam", Acta Tropica, vol. 141, (2015), pp. 88-96.

[18] S. Atique, S. S. Abdul, C. Y. Hsu and T. W. Chuang, "Meteorological influences on dengue transmission in Pakistan", Asian Pacific J. of Tropical Medicine, vol. 9, no. 10, (2016), pp. 954-961.

[19] V. S. H. Rao and M. N. Kumar, "A new intelligence-based approach for computer-aided diagnosis of dengue fever", IEEE Transactions on IT in Biomedicine, vol. 16, no. 1, (2012), pp. 112-118.

[20] N. Mohd Zainee and K. Chellappan, "A preliminary dengue fever prediction model based on vital signs and blood profile", in IECBES 2016 - IEEE-EMBS Conference on Biomedical Engineering and Sciences, (2017), pp. 652-656.

[21] J. A. Potts, R. V. Gibbons, A. L. Rothman, A. Srikiatkhachorn, S. J. Thomas, P. on Supradish, S. C. Lemon, D. H. Libraty, S. Green and S. Kalayanarooj, "Prediction of dengue disease severity among pediatric Thai patients using early clinical laboratory indicators", PLoS Neglected Tropical Diseases, vol. 4, no. 8, (2010), pp. 2-9.

[22] Z. T. Salim, U. Hashim, M. K. M. Arshad, M. A. Fakhri and E. T. Salim, "Frequency-based detection of female Aedes mosquito using surface acoustic wave technology: Early prevention of dengue fever", Microelectronic Engineering, vol. 179, (2010), pp. 83-90.

[23] J.-J. Tsai, K. Chokephaibulkit, P.-C. Chen, L.-T. Liu, H.-M. Hsiao, Y.-C. Lo and G. C. Perng, "Role of cognitive parameters in dengue hemorrhagic fever and dengue shock syndrome", Journal of biomedical science, vol. 20, no. 1, (2013), pp. 88.

[24] S. Nubenthan and C. Shalomy, "A wireless continuous patient monitoring system for dengue: Wi-Mon", in Proceedings of 6th National Con on Technology and Management, (2017), pp. 23-27.

[25] A. Redondi, M. Chirico, L. Borsani, M. Cesana and M. Tagliasacchi, "An integrated system based on wireless sensor networks for patient monitoring, localization and tracking", Ad Hoc Networks, vol. 11, no. 1, (2013), pp. 39-53.

[26] F. C. J. González, O. O. V. Villegas, D. E. T. Ramírez, V. G. C. Sánchez and H. O. Domínguez, "Smart multi-level tool for remote patient monitoring based on a wireless sensor network and mobile augmented reality", Sensors, vol. 14, no. 9, (2014), pp. 17212-172134.

[27] S. K. Sood and I. Mahajan, "Wearable IoT sensor based healthcare system for identifying and controlling chikungunya virus", Computers in Industry, vol. 91, (2017), pp. 33-44.

[28] P. Rani, V. Raychoudhury, S. S. Sandha and D. Patel, "Mobile health application for early disease outbreak-period detection", IEEE 16th International Conference on e-Health Networking, Applications and Services (Healthcom), (2014).

[29] N. R. Pandya, "Wireless Sensor Based Handy Patient Monitoring System", in 2016 IEEE 6th International Conference on Advanced Computing (IACC), (2016), pp. 634-638.

[30] H. Rallapalli and P. Bethelli, "IOT Based Patient Monitoring System", Int'l J. of Computing, Communications \& Instrumentation Engg, vol. 4, no. 1, (2017), pp. 115-118.

[31] C. D. A. Marques-toledo, C. M. Degener, L. Vinhal, G. Coelho, W. Meira, C. T. Codec and M. M. Teixeira, "Dengue prediction by the web: Tweets are a useful tool for estimating and forecasting Dengue at country and city level”, PLoS Negl Trop Dis, vol. 11, no. 7, (2017), pp. 1-20.

[32] N. Kerdprasop and K. Kerdprasop, "Remote Sensing Based Modeling of Dengue Outbreak with Regression and Binning Classification”, 2nd IEEE International Conference on Computer and Communications, (2016).

[33] S. S. Mathulamuthu, V. S. Asirvadam, S. C. Dass and B. S. Gill, "Cluster Based Regression Model on Dengue Incidence Using Dual Climate Variables", IEEE Conference on Systems, Process and Control, Melaka, Malaysia, (2016) December 16-18.

[34] G. Zhu, J. Hunter and Y. Jiang, "Improved Prediction of Dengue Outbreak Using the Delay Permutation Entropy", Proceedings IEEE International Conference on IoT, (2016), pp. 828-832.

[35] W. Anggraeni and L. Aristiani, "Using Google Trend data in forecasting number of dengue fever cases with ARIMAX method case study: Surabaya", Indonesia,Proceedings of 2016 Int. Conf. on Information and Communication Technology and Systems, (2017), pp. 114-118. 
[36] E. L. Estallo, E. M. Benitez, M. A. Lanfri, C. M. Scavuzzo and W. R. Almiron, "MODIS Environmental Data to Assess Chikungunya, Dengue, and Zika Diseases Through Aedes (Stegomia) aegypti Oviposition Activity Estimation", IEEE J. of Selected Topics in Applied Earth Observations and Remote Sensing, vol. 99, (2016), 5461-5466.

[37] C. Wu and P. J. Y. Wong, "Estimation of reproduction number of dengue transmission in a partially susceptible population", Int. Conf. Control, Automation, Robotics and Vision, (2017).

[38] J. Albinati, W. Meira and G. L. Pappa, "An Accurate Gaussian Process-Based Early Warning System for Dengue Fever", Proceedings of 5th Brazilian Conference on Intelligent Systems, (2017).

[39] N. S. Roslan, Z. A. Latif and N. C. Dom, "Dengue cases distribution based on land surface temperature and elevation", 7th IEEE Control and System Graduate Research, (2017) August.

[40] H. I. Datoc, R. Caparas and J. Caro, "Forecasting and data visualization of dengue spread in the Philippine Visayas island group", Int. Conf. on Info Intelligence, Systems and Applications, (2016).

[41] D. Rahmawati and Y. P. Huang, "Using C-support vector classification to forecast dengue fever epidemics in Taiwan", IEEE Int Conference on System Science and Engineering, (2016).

[42] Z. A. Latif and M. H. Mohamad, "Mapping of Dengue Outbreak Distribution Using Spatial Statistics and Geographical Information System", Proceedings of International Conf on Information Science and Security, (2015).

[43] J. Xiang, A. Hansen, Q. Liu, X. Liu, M. X. Tong, Y. Sun, S. Cameron, S. Hanson-Easey, G. S. Han, C. Williams, P. Weinstein, and P. Bi, "Association between dengue fever incidence and meteorological factors in Guangzhou", China, 2005-2014, Environmental R, vol. 153, (2017), pp. 17-26.

[44] A. E. Laureano-Rosario, J. E. Garcia-Rejon, S. Gomez-Carro, J. A. Farfan-Ale, and F. E. Muller-Karger, "Modelling dengue fever risk in the State of Yucatan, Mexico using regional-scale satellite-derived sea surface temperature", Acta Tropica, vol. 172, no. 4, (2017), pp. 50-57.

[45] M. N. Karim, S. U. Munshi, N. Anwar and M. S. Alam, "Climatic factors influencing dengue cases in Dhaka city: A model for dengue prediction”, Ind. J. of Medical Res, vol. 136, no. 1, (2012), pp. 32-39.

[46] A. L. Buczak, P. T. Koshute, S. M. Babin, B. H. Feighner and S. H. Lewis, "A data-driven epidemiological prediction method for dengue outbreaks using local and remote sensing data", BMC medical informatics and decision making, vol. 12, no. 124, (2012). 